\title{
Broad-Scale Hypotheses do not Account for Species Richness Patterns of Central American Mayflies
}

\author{
Rafael D. Loyola* \\ Departamento de Biologia Geral, Instituto de Ciências Biológicas, Universidade Federal de Goiás (UFG), Caixa Postal \\ 131, CEP 74001-970, Goiânia, GO, Brazil
}

\begin{abstract}
I performed an exploratory analysis of four broad-scale hypotheses (area availability, energy availability, habitat heterogeneity and geometric constraints) for changes in species richness over Central American mayfly species, and compared their outcomes at different taxonomic levels. I employed an eigenvector-based spatial filtering to control spatial autocorrelation effects and conducted multiple spatial eigenvector regressions to identify the strongest predictors of species, genus and family richness. The usefulness of higher-taxa as surrogates for species richness was assessed by Pearson correlations. Mayfly species richness is characterized by a patchy pattern. None of the variables accounted for observed patterns. Only area availability was an effective predictor of mayfly genus and family richness, although both habitat heterogeneity and energy presented marginal effects on genus richness. I did not observe any relationship between species and higher-taxa richness. Broad-scale hypotheses did not explain species richness patterns of mayflies, which instead can be explained by interactions among studied variables and spatial structure.
\end{abstract}

\section{INTRODUCTION}

Species are not uniformly or randomly distributed across the Earth's surface and many mechanisms have been proposed to explain broad-scale patterns (Whittaker et al. 2001, Willig et al. 2003). In fact, dozens of hypotheses were advanced in an attempt to explain the so-called latitudinal gradients, but many lacked a mechanism or evidence (Willig et al. 2003). For many years, global diversity studies were limited to the description of observed patterns, with few studies attempting to test general hypotheses (Willig et al. 2003). The macroecological approach, which deals with statistical patterns of ecologically informative variables, provoked a great advance in the study of such patterns (Brown 1995).

As a consequence of these recent advances, only five hypotheses are currently accepted as plausible for explaining the diversity gradients (Willig et al. 2003, Hillebrand 2004): (1) area availability - based on the premise that larger areas offer more opportunities for speciation and lower probability of extinction (Terborgh 1973); (2) energy availability - also called the 'productivity hypotheses', it states that higher productivity results in higher diversity, if other factors are kept constant (Pianka 1966); (3) evolutionary time - it assumes that diversity increases with a region's age so that older communities have more species than newer ones (Pianka 1966, Clarke \& Crame 2003); (4) habitat heterogeneity - it states that more complex habitats have more microhabitats than the simpler ones (August 1983), supporting more species due to different kinds of microhabitat exploitation; and (5) geometric constraints - this hypothesis proposes that

*Address for correspondence to this author at the Departamento de Biologia Geral, Instituto de Ciências Biológicas, Universidade Federal de Goiás (UFG), Caixa Postal 131, CEP 74001-970, Goiânia, GO, Brazil; E-mail: avispa@gmail.com

Handling Editor: Tamar Dayan environmental gradients are not necessary to generate latitudinal patterns in species richness (Colwell \& Hurt 1994, Willig et al. 2003), assuming the so-called Mid Domain Effect (Colwell \& Lees 2000). Nowadays, the major challenge is to test the predictions of existing hypotheses instead of proposing new ones.

Gaps in geographical patterns in species richness exist for several taxonomic groups (Heino 2002), and patterns and determinants of freshwater biodiversity are yet poorly known when compared to many terrestrial groups (Allan \& Flecker 1993, Vinson \& Hawkins 1998, 2003). At broad spatial scales, quantitative information on species richness patterns are largely lacking for many freshwater taxa (Abel et al. 2002). This can be explained by the fact that most freshwater research has usually focused on describing phenomena within or among local systems (Minshall 1988). Nonetheless, freshwater research would benefit from increased attention to broad-scale patterns in species richness given the emphasis on the effects of regional processes on local communities (Huston 1999, Cornell \& Lawton 2002).

Ideally, species-level datasets should be used in the study of biodiversity patterns. However, this requires substantially unpredictable amount of time, and in some cases, the highertaxon approach may be a shortcut (Balmford et al. 1996, Heino et al. 2003a). The utility of using surrogates for conservation evaluation and planning is, however, poorly developed for freshwater ecosystems (Heino \& Soininen 2008). Counting higher taxa (e.g., genus, family) instead of species has been used to some advantage (Williams \& Gaston 1994), and some recent studies (Grelle 2002, and references therein) showed that higher-taxon estimates of biodiversity could be used to understand broad-scale diversity patterns (see also Heino et al. 2003a). Patterns of higher taxa can be also used as a surrogate for historical components of diversity, because they represent spatial variation in the number of evolutionary lineages, and thus can be interpreted in terms of recent 
hypotheses on the importance of niche conservatism for richness patterns (Hawkins et al. 2006). Possible differences between the number of species/genus per locality can also suggest higher turnover and even speciation rates within different regions. Under a community ecology perspective, this can be interpreted as a result of different assembly rules organizing species communities. Therefore, investigating patterns of species, genus and family richness may provide some insights about how natural communities were assembled and how evolutionary processes, such as speciation and colonization/extinction dynamics, have evolved. The use of higher taxa bears most promise for stream ecosystems, because genus and family-level identifications have been successfully used in stream monitoring programs (Bailey et al. 2001, and references therein).

My goal in this study was to describe the mayfly species richness pattern found in Central America, and to perform an exploratory analysis of the 'area availability', 'energy availability', 'habitat heterogeneity' and 'geometric constraints' hypotheses on this insect group, in order to identify the most effective predictors of such patterns. Using species-level data on Central American mayflies I also compared the outcomes of these analyses at different taxonomic levels in order to investigate the utility of using higher taxa (i.e. genus and family) as surrogates of species level data accounting for taxon richness environmental patterns.

\section{METHODS}

\section{Mayfly Data}

Geographic data on all Central American mayfly species was from the Mayfly Central web site (http://www. entm.purdue.edu/Entomology/research/mayfly/mayfly.html). The data was originally compiled from McCafferty \& LugoOrtiz (1996), and contains the species distribution over seven countries of Central America: Belize, Guatemala, El Salvador, Honduras, Nicaragua, Costa Rica and Panama (Fig. 1). Central America presents high mayfly diversity, with 119 species distributed in 42 genera and 10 families, even though many of its habitats are threatened by deforestation, including both wet and dry tropical forests (McCafferty \& Lugo-Ortiz 1996).

\section{Species Richness and Environmental Factors}

Central America was divided into 59 equal area cells (quadrats) of $110 \times 110 \mathrm{~km}\left(1^{\circ} \times 1^{\circ}\right.$ at Equator). The geographical ranges of the 119 mayfly species present in the continent were redrawn over this grid, and the presence of each species in each cell was recorded. Species richness was defined as the number of species recorded in each cell.

The four major hypotheses associated with broad-scale richness patterns were expressed by the following variables: (1) area availability was defined as the number of grid cells

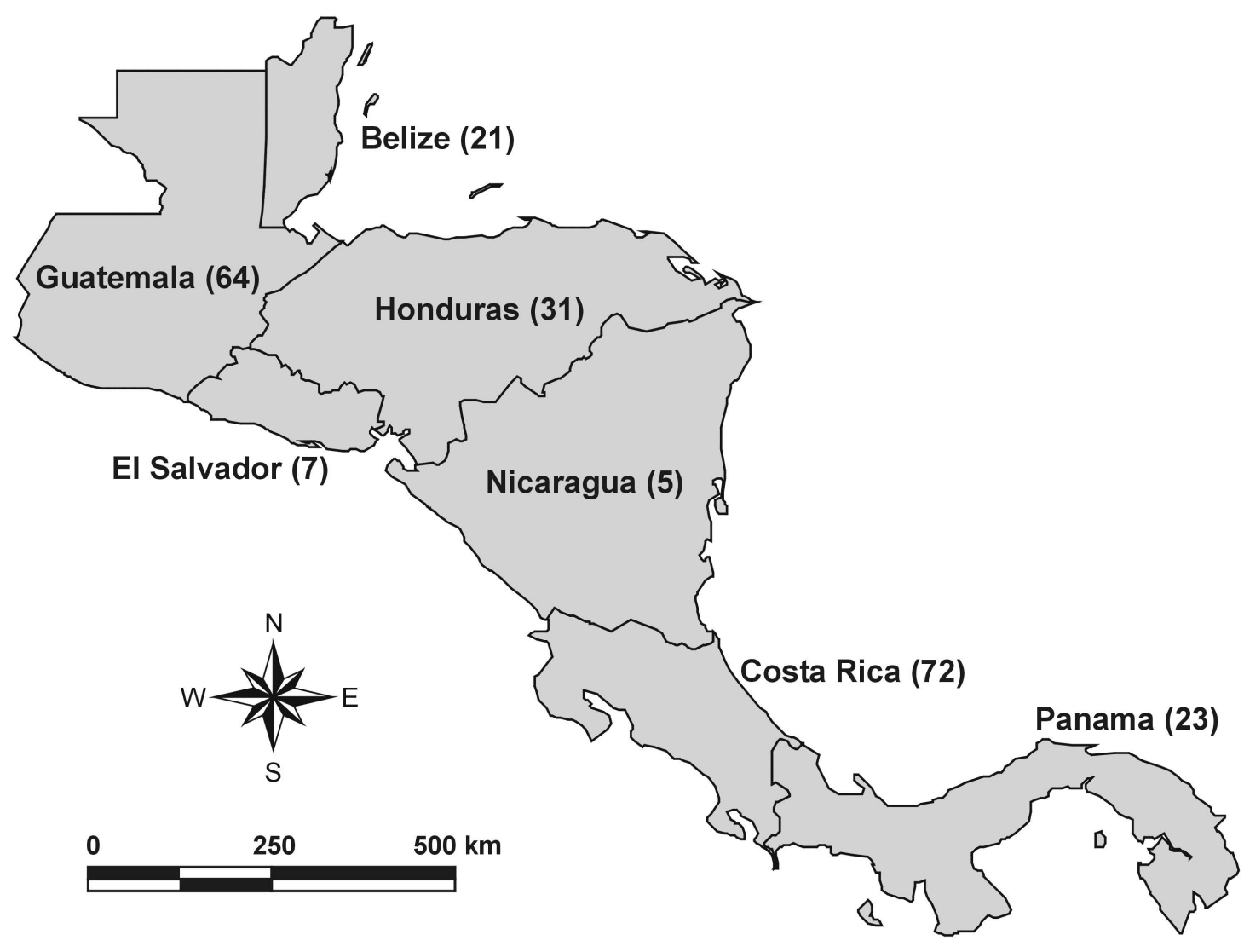

Fig. (1). Detail of Central America, the scope of this study. The number inside the parentheses indicates species richness found in each country. 
on the latitudinal band; (2) mean annual potential evapotranspiration (PET) was used as a surrogate for energy availability; PET data was obtained from the GEO Data Portal (http://geodata.grid.unep.ch). PET was calculated using adjusted values of mean monthly temperature surfaces and the mean day length table. Hence, this variable is intrinsically associated with the amount of energy directed to the Earth by the sun. Here, PET is referred as "energy availability" only to be in accordance with the hypothesis name. (3) I calculated the altitudinal range of each grid cell as a surrogate for habitat heterogeneity, assuming that areas with higher altitudinal ranges present a larger number of habitats, especially those associated with mountain streams, which are extremely important for mayfly species. For this, we took the altitudinal value of four randomized points at each grid and subtracted the lowest altitude from the highest altitude. Altitudinal data were obtained from U.S. Geological Survey's Hydro-1K (http://edc.usgs.gov/products/elevation/gtopo30/ gtopo30.html). Elevation is known to be associated with regional-scale diversity gradients (see Diniz-Filho \& Bini 2005). At the regional scale, areas with high topographic variability present higher habitat heterogeneity because topographic complexity benefits the existence of different microhabitats, with distinct local temperature, humidity, and vegetation type. Similarly to PET, elevation range is refereed here as "habitat heterogeneity" just in favor of the hypothesis name; and (4) a null model of species richness distribution, that assumes geometric constraints, was calculated following Willig \& Lyons (1998), as $2 p q \mathrm{~S}$, where $p$ and $q$ are the proportional distances between the limits of the geographical distribution of each mayfly family ( $p$ at extreme south, $0 ; q$ at extreme north, 1 ; with $\mathrm{p}+\mathrm{q}=1$ ), and $\mathrm{S}$ the total number of species within each family (Willig \& Lyons 1998).

\section{Data Analysis}

The lack of independence between pairs of observations across the geographical space (spatial autocorrelation) is commonly observed in ecological data (Legendre 1993). Moreover, grid-based diversity datasets in general are spatially autocorrelated (Rahbek \& Graves 2001, Diniz-Filho et al. 2003). Due to this phenomenon, when testing statistical hypotheses using standard methods (e.g., ANOVA and regression), the standard errors are usually underestimated when a positive autocorrelation is present, and consequently, Type I errors may be inflated (Legendre 1993, Diniz-Filho et al. 2003), in such way that more complex strategies for data analyses are required.

First, I analyzed spatial patterns in species richness, the environmental predictors and the residuals from the multiple regressions (see below), and estimated autocorrelation patterns using spatial correlograms constructed using Moran's I coefficients estimated at distinct distance classes. Moran's I coefficient is given by,

$$
I=\left(\frac{n}{S}\right)\left[\frac{\sum_{i} i \sum_{j} j\left(y_{i}-\bar{y}\right)\left(y_{j}-\bar{y}\right) w_{i j}}{\sum_{i}\left(y_{i}-\bar{y}\right)^{2}}\right]
$$

where $n$ is the number of samples (quadrats), $y_{i}$ and $y_{j}$ are the species richness in quadrats $i$ and $j, \bar{y}$ is the average of $y$ and $w_{i j}$ is an element of the matrix $\mathbf{W}$. In this matrix, $w_{i j}=1$ if the pair $i, j$ of quadrats is within a given distance class interval (indicating quadrats that are 'connected' in this class), and $w_{i j}=0$ otherwise. $S$ indicates the number of entries (connections) in the $\mathbf{W}$ matrix. The value expected under the null hypothesis of the absence of spatial autocorrelation is $-1 /(n-$ 1). Detailed computations of the coefficient and of its standard error are given in (Legendre 1993). Autocorrelation analyses were performed using SAM 3.0 (Rangel et al. 2006).

Moran's $I$ usually varies between -1.0 and 1.0 for maximum negative and positive autocorrelation, respectively. Non-zero values of Moran's $I$ indicate that richness values in quadrats connected at a given geographical distance are more similar (positive autocorrelation) or less similar (negative autocorrelation) than expected for randomly associated pairs of quadrats (Diniz-Filho et al. 2003). The number and definition of distance classes to be used in the correlograms is arbitrary, but a general methodological criterion is to maximize the similarity in the $S$-values (number of connections) for the different Moran's I coefficients, so that they are better comparable (Diniz-Filho et al. 2003). That is why I used two distinct distance classes in this study (see Results). It is important to note that the arbitrariness in the number of distance classes is not important in most cases, because the purpose of the analysis is to describe a continuous spatial process.

Spatially autocorrelated data sets present both a potential statistical problem, and an opportunity to recognize the importance and understand the causes of spatial structure in ecology (Legendre 1993, Diniz-Filho et al. 2003). One of these strategies includes the control of spatial autocorrelation by using modern statistical analysis. Here, I applied an eigenvector-based spatial filtering to evaluate spatial patterns in Central American mayflies and to control the effects of spatial autocorrelation. The method consists of using the geographical coordinates of each grid across a region, based on eigenanalyses of geographical distances, to establish a set of spatial filters (eigenvectors) expressing the spatial structure of the region at different spatial scales, which, in turn, could be used as additional predictors of the response variable (Diniz-Filho \& Bini 2005). This way, any remaining spatial structures in regression residuals would be taken into account, and so these models would not be affected by the problem of spatial autocorrelation (see Diniz-Filho \& Bini 2005 for details).

Using the spatial eigenvector regression analysis (i.e. a multiple regression that includes both environmental factors and the filters as explanatory variables), I established the amount of variation in richness that can be explained by each hypothesis. Running spatial autocorrelation analysis on regression residuals helped to interpret which part of spatial structure among cells are captured by each variable. That means that, if spatial filters and any other variables account for the complex spatial pattern of species distribution, the autocorrelation will not be present in the residuals and the regression model will not be biased by spatial autocorrelation (Diniz-Filho \& Bini 2005). Spatial eigenvector regressions were run using SAM 3.0 (Rangel et al. 2006). I ran the same analysis protocol for Central American mayfly genus and family richness (as response variables) in order to verify if the same factors are effective in explaining higher-taxon richness, if patterns of spatial autocorrelation are consistent 

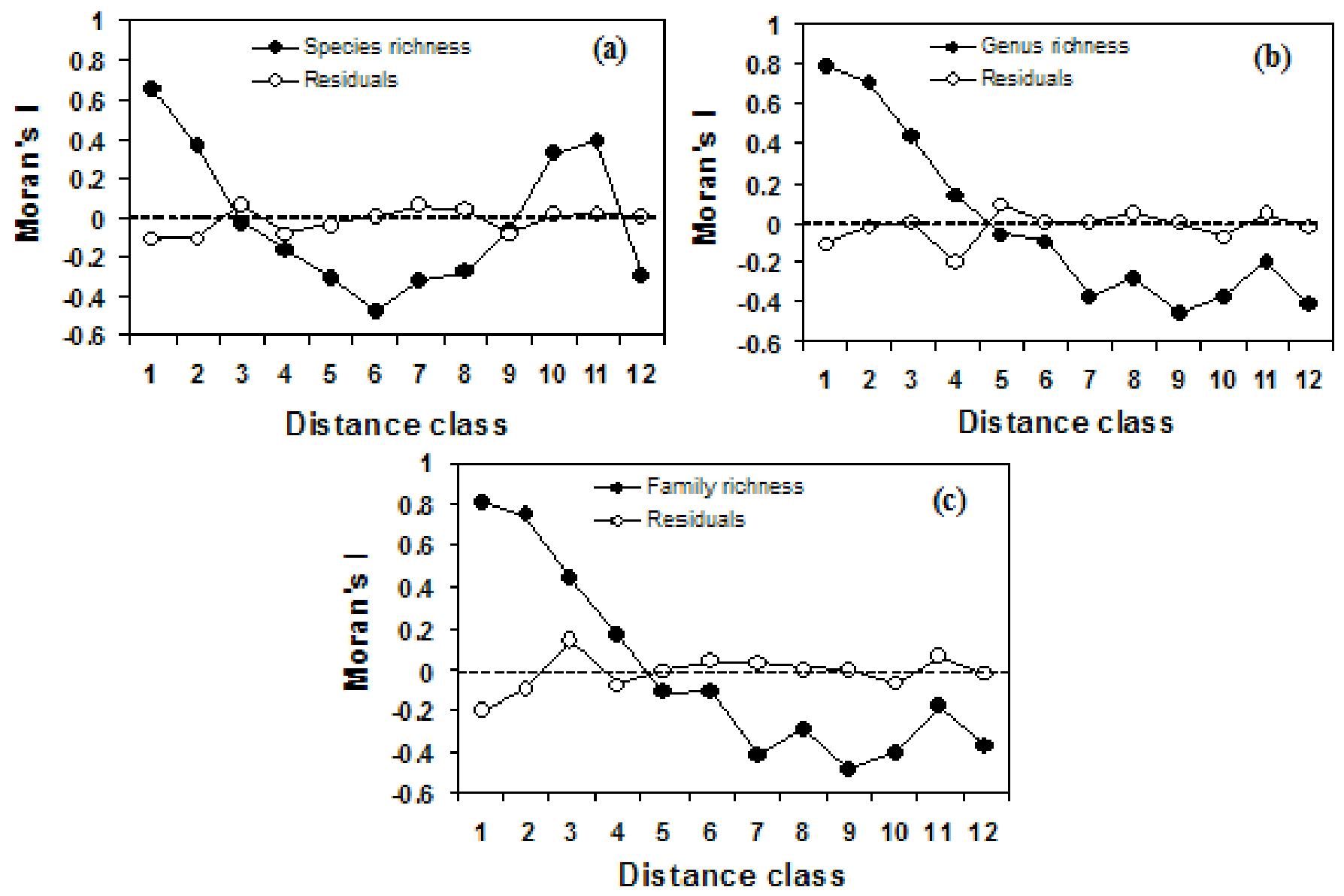

Fig. (2). Moran's I correlogram for Central American mayfly species (a), genus (b) and family (c) richness and the residual of spatial eigenvector regression model including area, PET, altitudinal range, the geometric constraint model, and the selected spatial filters as predictors.

among different taxonomic levels, and if higher-taxon analyses are useful to estimate the spatial pattern of mayfly species richness in Central America. Finally, I tested the congruence between the richness of species, genera and families using Pearson correlations.

\section{RESULTS}

I found a spatial pattern in mayfly species richness, with two major clusters of similar values. These clusters were positioned in opposite directions. As the degree of positive spatial autocorrelation decreased, the spatial pattern became more fragmented (Fig. 2a). At larger distance classes, a positive autocorrelation appeared again, generating the other cluster. In a similar way, mayfly genus and family richness were also patterned in space; nonetheless, positive autocorrelation exists only at short-distance classes (Fig. 2b, c).

For the explanatory variables (area, PET, altitudinal range and the geometric constraint model), a strong spatial structure in the first class appears for all of them (Fig. 3). Moderate short-distance autocorrelation coefficients were observed for PET, altitudinal range and the geometric constraint model. Area and altitudinal range showed a more patchy spatial structure with positive autocorrelation in the first distance classes, followed by less significant coefficients beyond these distances (Fig. 3a, c). The geometric constraint model showed a different pattern, with shortdistance positive spatial autocorrelation, less significant cor- relations at intermediate distances and positive autocorrelation at the largest distance classes (Fig. 3d).

The spatial eigenvector regression model, with all the four ecological factors and selected spatial filters as predictors, explained $80 \%$ of variation in mayfly species richness (Table 1). Comparing the partial regression coefficients of the predictor variables and their statistical significance, none of the variables explained the pattern of species richness observed (Table 1).

The multiple regression model explained $84 \%$ and $c a$. $85 \%$ of the genus and family richness observed, respectively (Table 1). Relative to mayfly genus and family richness, and contrary to the observed for species richness pattern, the comparison of multiple regression coefficients of the predictor variables and their statistical significance revealed that only area availability was significant in the model (except for the filters), although PET and altitudinal range showed a marginal effect on genus richness (Table 1). The residuals of all spatial eigenvector models were normally distributed; presented homocedasticity and did not present spatial autocorrelation, indicating that the regression models are not biased by this phenomenon (Fig. 2).

Finally, I observed only a weak correlation (with a rather low explained variance) between species richness and genus richness $\left(\mathrm{R}^{2}=0.090, \mathrm{P}<0.05\right)$ and no meaningful correlation between species and family richness $\left(\mathrm{R}^{2}=0.060, \mathrm{P}>\right.$ 

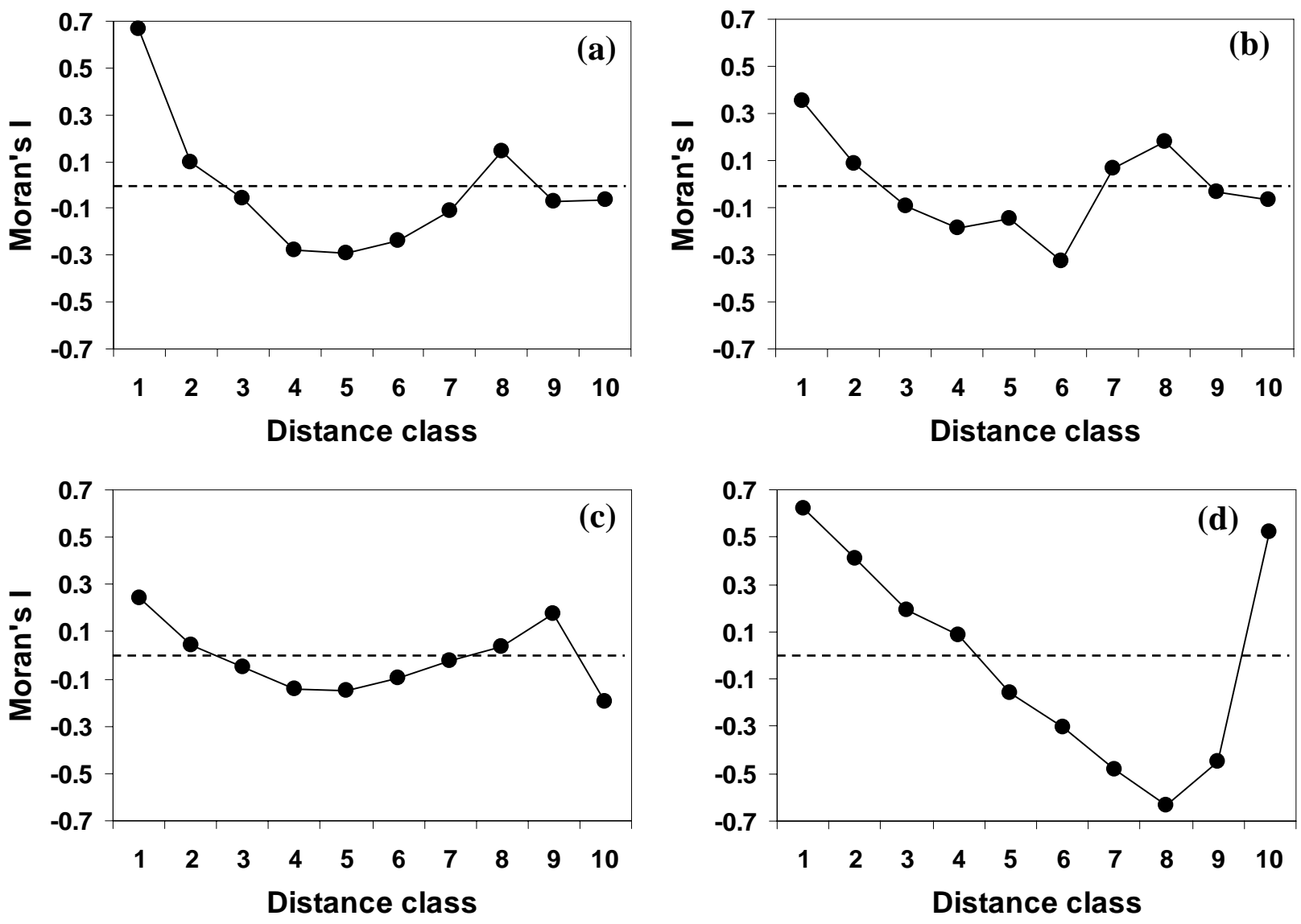

Fig. (3). Moran's I correlograms for (a) area, (b) PET, (c) altitudinal range, and (d) the geometric constraint model of species distribution. All correlograms are significant at $\mathrm{P}<0.01$.

$0.05)$, indicating that generic and family levels are inadequate as surrogates for mayfly species richness.

\section{DISCUSSION}

The analyzed variables were sufficient in generating an explanatory model for the pattern of mayfly species, genus and family richness found in Central America. However, none of the explanatory variables is capable of explaining the pattern here observed alone. By contrast, the spatial filters were highly capable of explaining variation in taxonomic richness. According to my results, I can conclude that the energy availability (PET) and geometric constraints do not exert any influence on mayfly species and family richness, at the analyzed geographical scale, because none of the regression coefficients was significant nor this variable presented a consistent pattern across the continent.

\section{The Importance of Habitat Heterogeneity}

Recent studies have pointed out productivity as the primary factor generating diversity gradients, supporting the energy hypothesis, which was already demonstrated for plants O'Brien et al. 2000), marine gastropods (Roy et al. 1998), ants (Kaspari et al. 2000), kissing bugs (Rodriguero \& Gorla 2004), birds (Rahbek \& Graves 2001, Diniz-Filho et al. 2004) and mammals (Ruggiero \& Kitzberger 2004). In some of these studies, as in the present one, habitat heterogeneity also constitutes a variable capable of explaining the species richness pattern, although always as a secondary factor. The present study revealed that altitudinal range was not an effective predictor of mayfly richness, but it deserves additional study. There is good evidence suggesting that habitat heterogeneity (and beta-diversity) increases towards the Equator (Koleff et al. 2003), even though not all studies confirm this pattern (Gaston \& Blackburn 1996). The great species turnover in Central America is mainly related to the high habitat heterogeneity found in this continent. Central America has large extensions of tropical Atlantic moist forests, montane forests and dry forests, which provide not only habitat diversity, but also important topographic variability, a factor known to increase benthic fauna diversity (Vinson \& Hawkins 1998, Heino et al. 2003b). It is also important to note that mayfly nymphs inhabit unpolluted water, and such vegetation, along with altitudinal variation, favors the existence of preserved mountain streams. Other environmental factors (e.g. water chemistry) were reported to be related with stream invertebrate diversity (Vinson \& Hawkins 1998) and Heino et al. (2003b) found that mayfly species richness were negatively related to gradients in water acidity and color. Therefore, it is possible that measures of different 
Table 1. Partial Regression Coefficients of the Multiple Regression Models ( $\beta$ ), $t$ Statistics and Associated P-Values for Central America Mayfly Species (a), Genus (b) and Family (c) Richness Regressed Against Environmental Variables, the Null Model and Eigenvectors (Spatial Filters), According to Ordinary Least Square Model (OLS)

\begin{tabular}{|c|c|c|c|c|c|c|c|c|c|}
\hline & \multicolumn{3}{|c|}{ (a) $R^{2}=0.797, F=21.367 p<0.00$} & \multicolumn{3}{|c|}{ (b) $R^{2}=0.840, F=45.508 p<0.00$} & \multicolumn{3}{|c|}{ (c) $R^{2}=0.846, F=47.822 p<0.00$} \\
\hline PET & 0.039 & 0.447 & 0.657 & 0.118 & 1.800 & 0.078 & 0.102 & 1.585 & 0.119 \\
\hline Alt. Range & -0.084 & -1.024 & 0.311 & 0.131 & 1.954 & 0.056 & 0.089 & 1.350 & 0.183 \\
\hline Filter 1 & 0.360 & 3.594 & 0.000 & 0.002 & 9.093 & 0.000 & -0.628 & -9.028 & 0.000 \\
\hline Filter 2 & -0.389 & -4.538 & 0.000 & 0.002 & -5.466 & 0.000 & -0.293 & -4.755 & 0.000 \\
\hline Filter 3 & -0.399 & -4.427 & 0.000 & - & - & - & - & - & - \\
\hline Filter 4 & -0.402 & -5.19 & 0.000 & - & - & - & - & - & - \\
\hline
\end{tabular}

types, and availability of local freshwater ecosystems, might be more strongly related to their regional patterns of species richness.

\section{The Area Hypothesis and Central America Geometric Constraints}

Some authors (e.g. Whittaker et al. 2001) criticized the area hypothesis arguing that the amount of area per se cannot explain the latitudinal gradient in species diversity, and that it should be removed from macroecological analyses since it is not a primary factor begetting diversity. However, other authors (Blackburn \& Gaston 1997, Rosenzweig 2005) found support for this hypothesis, and area availability was indeed an effective predictor of mayfly genus and family richness in this study, although this variable was not useful in explaining mayfly species richness.

Similarly, geometric constraints were not capable of explaining Central American mayflies species, genus or family richness.. The test of geometric constraints asks whether a randomized pattern can reproduce the real data pattern, excluding from the test any other important features, such as environment variables (Rangel \& Diniz-Filho 2003). In previous studies, Rangel \& Diniz-Filho (2005) suggest that the mid-peak spatial pattern in species richness predicted by geometric constraint models could be interpreted as a macroecological reflex of neutral processes acting at population level over a bounded domain. The geometric constraints effects were not observed here, and they probably would have been pronounced if mayfly species were short-distance migrants in relation to the continent, causing species' range cohesion. However, mayfly species colonize areas mainly through river flow along river basins, extending their geographic distribution within the region.

\section{Should a Higher-Taxon Approach be Used for Central American Mayflies?}

The use of higher-taxon richness as a surrogate of biodiversity appears attractive because it should be substantially cheaper to identify specimens from survey samples to a higher-taxon level than to the species level (Harker 1999). Moreover, if a strong relationship can be demonstrated, then it might be possible to use the spatial distribution of highertaxon richness to estimate the distribution of species richness more widely (Williams \& Gaston 1994). For freshwater ecosystems, the utility of using surrogates for conservation evaluation and planning is still poorly developed and such lack of knowledge is particularly problematic because (1) they present high levels of biodiversity compared to their area, (2) there is an absence of species-level information for many taxonomic groups, and (3) they suffer with high anthropogenic pressure worldwide (Ricciardi \& Rasmussen 1999, Abell et al. 2002, Strayer 2006). However, the absence or weakness of such correlation, along with different variables responsible for the species and genus/family richness found in the present study, indicate that a higher-taxon approach should not be used for Central American mayflies. It is important to note that differences between these levels are clearly related to biogeographical and historical colonization processes of the entire continent. Therefore, regions with more species do not necessarily contain more information about diversification processes at different hierarchical levels (Hawkins et al. 2006, Tôrres \& Diniz-Filho 2004). In this case, decisions about priorities are not easy, and counting species is more informative regarding evolutionary processes and broad-scale diversity patterns.

\section{The Role of History and Scale}

Environmental variables are not the only determinants of species distributions, which are also affected by dispersal limitation, climate, and historical limitations (Lomolino et al. 2006). Assemblage variation across geographical locations should be seen as a pure spatial component in variance partitioning analyses (Cottenie 2005); however, I observed a significant spatial component for higher taxonomic levels, although the distributions of genera and families should be much wider than those of species, and therefore, they should exhibit less spatially-structured variability than species (Heino \& Soininen 2008). This finding may be related to 
scale given that at larger-scales (i.e. from continental to global), higher taxon richness showed strong geographical variability (Balmford et al. 1996). If this is the case, our study indicates that spatial variability in higher-taxon assemblage structure and richness at the regional scale is also possible. Alternatively, my findings could be related to the rather low number of families, as for studies comprising higher number of families and taxonomic groups (e.g. stoneflies and caddisflies), a meaningful correlation between taxonomic levels in species richness might be found (Heino $\&$ Soininen 2008).

\section{CONCLUDING REMARKS}

This paper illustrates how different mechanisms can be tested using a single framework, which can be useful for reaching more general conclusions about the determinants of species and other taxonomic level richness. The combined effects of environmental variables and their interaction with spatial structure explained more than $c .82 \%$ of the variation in mayfly species, genus and family richness. In contrast to other studies (Diniz-Filho et al. 2004), my results suggest that turnover rates and scaling effects are useful for detecting faunal changes and beta diversity, and may represent a strong explanation for broad-scale patterns in species richness. Furthermore, the analyses performed here showed that generic and family level richness are not acceptable surrogates for species richness since these taxonomic levels are very weakly correlated, and therefore, are not useful in studies of mayfly richness patterns in Central America.

\section{ACKNOWLEDGEMENTS}

I am indebted to Thomas M. Lewinsohn, Jani Heino, José Alexandre F. Diniz Filho, and Daniel Brito for their helpful suggestions, critical reading, and language improvement of previous versions of the manuscript. Two anonymous referees and Tamar Dayan helped improve the paper. R.D.L. was supported by CNPq (140267/2005-0).

\section{REFERENCES}

Abell, R (2002) Conservation biology for the biodiversity crisis: a freshwater follow-up. Conservation Biology, 16, 1435-7.

Abell, RA, Olson, DM, Dinerstein, E, Hurley, PT, Diggs, DJ, Eichbaum, W, Walters, S, Wettengel, W, Allnutt, T, Loucks, CJ, Hedao, P (2002) Freshwater ecoregions of North America: a conservation assessment, Island Press, Washington, DC.

Allan, JD \& Flecker, AS (1993) Biodiversity Conservation in Running Waters. Bioscience, 43, 32-43.

August, PV (1983) The role of habitat complexity and heterogeneity in structuring tropical mammal communities. Ecology, 64, 1495-507.

Bailey, RC, Norris, RH \& Reynoldson, TB (2001) Taxonomic resolution of benthic macroinvertebrate communities in bioassessments. Journal of North America Benthological Society, 20, 280-6.

Balmford, A, Green, MJB \& Murray, MG (1996) Using higher-taxon richness as a surrogate for species richness regional tests. Proceedings of the Royal Society of London Series B, 263, 1267-74.

Blackburn, TM \& Gaston, KJ (1997) The relationship between geographic area and the latitudinal gradient in species richness in New World birds. Evolutionary Ecology, 11, 195-204.

Brown, JH (1995) Macroecology, University of Chicago Press, Chicago.

Clarke, A \& Crame, JA (2003) In: Blackburn TM \& Gaston KJ (Eds). Macroecology: concepts and consequences, Blackwell Publishing, Malden, 130-51.

Colwell, RK \& Hurtt, GC (1994) Nonbiological gradients in species richness and a spurious rapoport effect. The American Naturalist, 144, 570-95.
Colwell, RK \& Lees, DC (2000) The mid-domain effect: geometric constraints on the geography of species richness. Trends in Ecology \& Evolution, 15, 70-6.

Cornell, HV \& Lawton, JH (2002) Species interactions, local and regional processes, and limits to the richness of ecological communities - a theoretical perspective. Journal of Animal Ecology, 61, 1-12.

Cottenie, K (2005) Integrating environmental and spatial processes in ecological community dynamics. Ecology Letters, 8, 1175-82.

Diniz-Filho, JAF \& Bini, LM (2005) Modelling geographical patterns in species richness using eigenvector-based spatial filters. Global Ecology and Biogeography, 14, 177-85.

Diniz-Filho, JAF, Bini, LM \& Hawkins, BA (2003) Spatial autocorrelation and red herrings in geographical ecology. Global Ecology and Biogeography, 12, 53-64.

Diniz-Filho, JAF, Rangel, TFLVB \& Hawkins, BA (2004) A test of multiple hypotheses for the species richness gradient of South American owls. Oecologia, 140, 633-8.

Gaston, KJ \& Blackburn, TM (1996) The tropics as a museum of biological diversity: analysis of the new world avifauna. Proceedings of the Royal Society of London Series B, 263, 63-8.

Grelle, CEV (2002) Is higher-taxon analysis a useful surrogate of species richness in studies of Neotropical mammal diversity? Biological Conservation, 108, 101-6.

Harker, J (1999) Mayflies Naturalists' Handbooks Nº 13, Richmond Publishing Co Ltd.

Hawkins, BA, Diniz-Filho, JAF, Jaramillo, CA \& Soeller, SA (2006). Posteocene climate change, niche conservatism, and the latitudinal diversity gradient of new world birds. Journal of Biogeography, 33, $770-80$.

Heino, J (2002) Concordance of species richness patterns among multiple freshwater taxa: a regional perspective. Biodiversity and Conservation, 11, 137-47.

Heino, J \& Soininen, J (2008) Are higher taxa adequate surrogate for species-level assemblage patterns and species richness in stream organisms? Biological Conservation, 137, 78-89.

Heino, J, Muotka, T, Paavola, R \& Paasivirta, L (2003a) Among-taxon congruence in biodiversity patterns: can stream insect diversity be predicted using single taxonomic groups? Canadian Journal Fisheries and Aquatic Science, 60, 1039-49.

Heino, J, Muotka, T \& Paavola, R. (2003b) Determinants of macroinvertebrate diversity in headwater streams: regional and local influences. Journal of Animal Ecology, 72, 425-34.

Hillebrand, H (2004) On the generality of the latitudinal diversity gradient. The American Naturalist, 163, 192-211.

Huston, MA (1999) Local processes and regional patterns: appropriate scales for understanding variation in the diversity of plants and animals. Oikos, 86, 393-401

Kaspari, M, O'Donnell, S \& Kercher, JR (2000) Energy, density, and constraints to species richness: ant assemblages along a productivity gradient. The American Naturalist, 155, 280-93.

Koleff, P, Lennon, JJ \& Gaston, KJ (2003) Are there latitudinal gradients in species turnover? Global Ecology and Biogeography, 12, 483-98.

Legendre, P (1993) Spatial Autocorrelation: trouble or new paradigm? Ecology, 74, 1659-73.

Lomolino, MV, Riddle, BR \& Brown, JH (2006) Biogeography, Sinauer Associates, Sunderland, Mass.

McCafferty, WP \& Lugo-Ortiz, CR (1996) Los efemerópteros de América Central. Revista Nicaragüense de Entomología, 35, 19-28.

Minshall, GW (1988) Stream ecosystem theory: a global perspective. Journal of North America Benthological Society, 7, 263-88.

O'Brien, EM, Field, R \& Whittaker, RJ (2000) Climatic gradients in woody plant tree and shrub diversity: water-energy dynamics, residual variation, and topography. Oikos, $89,588-600$.

Pianka, ER (1966) Latitudinal gradients in species diversity: a review of concepts. The American Naturalist, 100, 33-46.

Rahbek, C \& Graves, GR (2001) Multiscale assessment of patterns of avian species richness. Proceedings National Academy of Science of the USA, 98, 4534-9.

Rangel, TFLVB \& Diniz-Filho, JAF (2005) Neutral community dynamics, the mid-domain effect and spatial patterns in species richness. Ecology Letters, 8, 783-90.

Rangel, TFLVB \& Diniz-Filho, JAF (2003) Spatial patterns in species richness and the geometric constraint simulation model: a global analysis of mid-domain effect in Falconiformes. Acta Oecologica, 24, 203-7. 
Rangel, TFLVB, Diniz-Filho, JAF \& Bini, LM (2006) Towards an integrated computational tool for spatial analyses in macroecology and biogeography. Global Ecology and Biogeography, 15, 321-7.

Ricciardi, A \& Rasmussen, JB (1999) Extinction rates of North American freshwater fauna. Conservation Biology, 13, 1220-2.

Rodriguero, MS \& Gorla, DE (2004) Latitudinal gradient in species richness of the new world triatominae reduviidae. Global Ecology and Biogeography, 13, 75-84.

Rosenzweig, ML (2005) In: Blackburn, TM \& Gaston, KJ (Eds) Macroecology: concepts and consequences, Blackwell Publishing, Malden, 130-51.

Roy, K, Jablonski, D, Valentine, JW \& Rosenberg, G (1998) Marine latitudinal diversity gradients: tests of causal hypotheses. Proceedings National Academy of Science of the USA, 95, 3699-702.

Ruggiero, A \& Kitzberger, T (2004) Environmental correlates of mammal species richness in South America: effects of spatial structure, taxonomy and geographic range. Ecography, 27, 401-16.

Strayer, DL (2006) Challenges for freshwater invertebrate conservation. Journal of North America Benthological Society, 25, 271-87.

Terborgh, J (1973) Notion of favorableness in plant ecology. The American Naturalist, 107, 481-501.
Tôrres, NM \& Diniz-Filho, JAF (2004) Phylogenetic autocorrelation and evolutionary diversity of carnivora mammalia in conservation units of the new world. Genetic and Molecular Biology, 27, 511-6.

Vinson, MR \& Hawkins, CP (1998) Biodiversity of stream insects: variation at local, basin, and regional scales. Annual Review of Entomology, 43, 271-93.

Vinson, MR \& Hawkins, CP (2003) Broad-scale geographical patterns in local stream insect genera richness. Ecography, 26, 751-67.

Whittaker, RJ, Willis, KJ \& Field, R (2001) Scale and species richness: towards a general, hierarchical theory of species diversity. Journal of Biogeography, 28, 453-70.

Williams, PH \& Gaston, KJ (1994) Measuring more of biodiversity: can higher-taxon richness predict wholesale species richness? Biological Conservation, 67, 211-7.

Willig, MR, Kaufman, DM \& Stevens, RD (2003) Latitudinal gradients of biodiversity: pattern, process, scale, and synthesis. Annual Review Ecology Evolution and Systematics, 34, 273-309.

Willig, MR \& Lyons, SK (1998) An analytical model of latitudinal gradients of species richness with an empirical test for marsupials and bats in the new world. Oikos, 81, 93-8.

(C) Rafael D. Loyola; Licensee Bentham Open.

This is an open access article licensed under the terms of the Creative Commons Attribution Non-Commercial License (http://creativecommons.org/licenses/by$\mathrm{nc} / 3.0 /$ ), which permits unrestricted, non-commercial use, distribution \& reproduction in any medium, provided the work is properly cited. 